\title{
Bibliografía de Ricardo Rojas
}

T A obra del maestro argentino Ricardo Rojas (1882-1957) es fecunda y $\perp$ múltiple. Este intento personal ha sido realizado con la esperanza de iniciar con algún detalle más bibliográfico un futuro y minucioso fichero de las distintas publicaciones del autor. Tal esfuerzo requeritá con toda seguridad la colaboración de admiradores, discípulos y entusiastas del maestro ejemplar, y agradeceríamos toda sugerencia ampliatoria para completar estas páginas.

Faltan - voy anticipándome con sinceridad a las críticas negativas-, supongo, algunos folletos y hubiera preferido hacer un ordenamiento cronológico de sus muchos ensayos, cuentos, artículos o noticias preliminares, que comprenden el duro y permanente batallar de un orientador y crítico literario, poeta e historiador. Con sólo detenernos a ordenar el material que él mismo había destinado a sus Obras Completas, encontramos un total de cuarenta volúmenes. Las dispersas revistas y sus continuos aportes como periodista of recen un campo difícil, como se comprenderá, de organización.

También las fuentes críticas a esta bibliografía de Rojas han quedado truncas. El recordado volumen que publicó una comisión de homenaje, titulado La obra de Rojas (XXV años de labor literaria, Buenos Aires, I903-I928; Librería "La Facultad", I928, 590 págs.), sigue siendo la fuente más consultada, pero hoy día podriamos citar abundante material que ha ido estudiando los escritos de Ricardo Rojas, tanto en América como en Europa, a cargo de prestigiosos investigadores en forma actualizada, especialmente por sus aspectos teatrales y filosóficos relacionados con lo español y lo americano, corrientes monitoras dentro de su vasta doctrina universal.

Señalo mi agradecimiento a don Ismael Moya por los aportes fundamentales con que ha querido contribuir a esta primera labor mía. 


\section{BIBLIOGRAFIA DE RICARDO ROJAS}

\section{POESİAS}

La victoria del bombre. (I900-1903). Poema. Imprenta Europea de M.

A. Rosas, Bs. As., I903 (con retrato por Araujo). [Recogido en Poesías, Bs. As. I923; y en edición de la Editorial Losada, S. A., Bs. As. I95 I].

Las lises del blasón. (I904-I9II). Poemas. Martín García, librero editor,

Bs. As. I9r. [Contiene además, El ocio lírico y La respuesta de Loxias].

La sangre del sol. Poema. Publicado en La Nación, 1915. [Recogido en Poesías, Bs. As. I923; y en edición de la Editorial Losada, S. A. Bs. As. I95I].

Canciones. Poemas. Ediciones Selectas "América" (año II, número 20), Bs. As. I920.

Los Cantos de Perséfona. (I906-I921). [Recogidos en Poesiats, Bs. As. I923; y en edición de la Editorial Losada, S. A., Bs. As. I95I].

Poesías. En Obras de Ricardo Rojas, Librería "La Facultad", Juan Roldán y Cía., Bs. As. I923. (Impresa por J. Pueyo, Madrid). [Contiene: El ocio lírico; La victoria del hombre; La sangre del sol; Los lises del blasón; La respuesta de Loxias; Cantos de Perséfona; Oda de las banderas].

Oda de las banderas. Poema. Publicado en La Nación, I92r. [Recogido en Poesias, Bs. As. 1923; y en edición de la Editorial Losada, S. A., Bs. As. I95I].

La victoria del bombre y otros cantos. En Obras Completis de Ricardo Rojas, Vol. 9, Editorial Losada, S. A., Bs. As. I951. [Contiene: La victoria del bombre; Los lises del blasón; Poemas varios: Canciones de Perséfona; La sangre del sol; El nuevo Ollantay; Oda de las banderas; Terruño (I920-1940); El albatros; y Tres romances de Eurindial.

Oda latina. [Texto original en hexámetros romanceados, seguidos de una traducción en latín y de otras versiones en lenguas modernas]. Editorial Guillermo Kraft Ltda., Bs. As. I954.

II. PROSA

El país de la selva. Garnier Hermanos, Libreros-Editores, París, 1907. En Obras de Ricatdo Rojas", tomo r6, Librería "La Facultad", Juan 
Roldán y Cía., Bs. As. I925. En la Revista Leoplán, Bs. As. I938. Editorial Guillermo Kraft Ltda., ilustraciones de Alfredo Gramajo Gutiérrez, Bs. As., I946. [Ver, Discografía].

El alma española. Casa Sempére, editor, Valencia, I908.

Cosmópolis. Garnier Hermanos, Libreros-Editores, París, r9o8.

Cartas de Europa. Editorial Sopena, Barcelona, r908. M. Rodríguez Giles, editor, Bs. As. I908 (2: edición).

La restauración nacionalista. (Informe sobre educación). Edición del Ministerio de Justicia e Instrucción Pública, Bs. As. I909. [Crítica de la educación argentina y bases para una reforma del estudio de las humanidades]. En Obras de Ricardo Rojas, tomo 4, Librería "Ia Facultad", Juan Roldán y Cía., Bs. As. I922.

Blasón de plata. [Meditaciones y evocaciones de Ricardo Rojas; sobre el abolengo de los argentinos]. En La Nación, I910; Martín García, Librero-Editor, Bs.As. I912. En Obras de Ricardo Rojas, tomo r, Librería "La Facultad", Juan Roldán y Cía., Bs.As., I922. Editorial Losada, S.A., Colección Biblioteca Contemporánea, Bs.As. r94I; (en

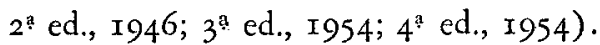

La Universidad de Tucumán. [Tres conferencias]. Librería Argentina de Enrique García (Impr. Coni), Bs.As. r9r5.

$L a$ argentinidad. (Ensayo histórico sobre nuestra conciencia nacional en la gesta de la emancipación, I810-1816). Libreria "La Facultad", de Juan Roldán y Cía., Bs.As. I9I6. En Obras de Ricardo Rojas, tomo 3, Librería "La Facultad", Juan Roldán y Cía., Bs.As. I922. Historia de la literatura argentina. [Primer Premio Nacional de Letras]. Edición de la Librería "La Facultad", de Juan Roldán y Cía. (Impr. Coni) : Los gauchescos (I9I7); Los coloniales (I9I8); Los proscrip. tos (I9r9); y Los modernos (I922). (En cuatro grandes tomos ilustrados). En Obras de Ricardo Rojas, dividida en ocho volúmenes; Librería "La Facultad", Juan Roldán y Cía., Bs. As. I924-I925. (Tomos 8 y 9: Los gauchescos, I y II, en I924; tomos io y II: Los coloniales, I y II, en I924; tomos I2 y I3: Los proscriptos, I y II, en I925; tomos I4 y I5: Los modernos, I y II, en I925). En Obras Completas de Ricando Rojas, Vol. I, Editorial Losada, S.A., Bs.As. 1948. [Dividida en ocho volúmenes, publicados los seis primeros en I948 y los siguientes en I949; comprenden la primera serie de esta nueva reedición ordenada de sus Obras Completas con esta numeración: I y 2, Los gauchescos; 3 y 4, Los coloniales; 5 y 6, Los proscriptos; 7 y 8, Los modernos. La edición lleva además un Post- 
scriptum y un Apéndice, complementándose los ocho volúmenes con un Indice Alfabético - que comprende Nombres, Obras y Materiasa cargo de Juan Canter, Nilda Celia Moya y Federico E. Alvarez $\rfloor$. Los arquetipos. [Seis oraciones: Belgrano; Güemes; Sarmiento; Pellegrini; Ameghino; Guido Spano]. En Obras de Ricardo Rojas, tomo 2, Librería "La Facultad", Juan Roldán y Cía., Bs.As. 1922.

Eurindia. (Ensayo de estética fundado en la experiencia histórica de las culturas americanas). En Obras de Ricardo Rojas, tomo 5, Librería "La Facultad", Juan Roldán y Cía., Bs.As., I924; Editorial Losada, S.A., Bs.As. I942. En Obras Completas de Ricardo Rojas, Vol. 24, Editorial Losada, S.A., Bs.As. I951.

Discursos. En Obras de Ricardo Rojas, tomo 6, Librería "La Facultad", Juan Roldán y Cía., Bs.As. I924.

La guerra de las naciones. En Obras de Ricardo Rojas, tomo 7, Libreria "La Facultad", Juan Roldán y Cía., Bs.As. I924.

Documentos del Decanato (I92I-I924). Facultad de Filosofía y Letras, Imprenta de la Universidad, Bs.As. r924.

Las provincias. En Obras de Ricardo Rojas, tomo 17, Librería "La Facultad", Juan Roldán y Cía., Bs.As. r927.

El Cristo Invisible. [Tres diálogos filosóficos]. En Obras de Ricardo Rojas, tomo I8, Librería "La Facultad", Juan Roldán y Cía., Bs.As., I927; $2^{\text {a }}$ edición (Idem); $3^{\mathrm{a}}$ edición, r928. (Impr. Hernández y Galo Sáez, Madrid).

Discursos del Rector (I926-1930). Facultad de Filosofía y Letras, Imprenta de la Universidad, Bs.As. I930.

La historia en las escuelas. Madrid, 1930. [Segunda parte de La restauración nacionalista].

Silabario de la decoración americana. Librería "La Facultad", Juan Roldán y Cía., Bs.As. 1930. En Obras Completas de Ricardo Rojas, Vol. 29, Editorial Losada, S.A., Bs.As. 1953.

El radicalismo de mañana. L.J.Rosso, editor, Bs.As. I931. [2* edición, con varios documentos no incluidos en ediciones posteriores, Bs.As. I932]. Editorial Losada, S.A., Bs.As. 1946.

Ei Santo de la Espada. Vida del General San Martín. Librerías Anaconda, Tall. Gráf. Rosso, Bs.As. 1933; I937; 1939. Editorial Losada, S.A., Bs.As. I945; 2a, I946; $3^{\text {a }}$, r947; $4^{\text {a }}$, r948; 5, I951. Editorial Losada, S.A., Bs.As., r950. [Edición ilustrada especial con diez y seis dibujos de Antonio Berni]. 
Cervantes. Librería "La Facultad", Juan Roldán y Cía., Bs.As. 1935 (Impr. López). Editorial Losada, S.A., Bs.As. 1948.

Retablo Español. Editorial Losada, S.A., Bs.As. 1938. En Obras Completas de Ricardo Rojas, Vol. 25, Editorial Losada, S.A., Bs.As., I948. El Profeta de la Pampa, Vida de Sarmiento. Editorial Losada, S.A., Bs.As. 1945; 1946; 1948.

Archipiélago (Tierra del Fuego). Publicado en La Nación, agosto de I94I hasta enero de 1942. Editorial Losada, S.A., Bs.As. 1942. En Obras Completas de Ricardo Rojas, Vol. I6, Editorial Losada, S.A., Bs.As. I947.

Un titán de los Andes. Editorial Losada, S.A., Bs.As. I949. (Col. Azul y Blanco).

La entrevista de Guayaquil. En Obras Completas de Ricardo Rojas, Vol., 30, Editorial Losada, S.A., Bs.As., I950.

Ensayo de critica bistórica sobre episodios de la vida internacional argentina. Editorial Raigal, Bs.As., I95r.

III. TEATRO

Elelin. (Drama en tres actos y en verso). Librería y Editorial "La Facultad", Bs.As., I929.

La Casa Colonial. En la revista Nosotros, $2^{\text {a }}$ época, año II, tomo VI, núms. 22 y 23, enero y febrero de 1938.

Ollantay. Tragedia de los Andes. Editorial Losada, S.A., Bs.As., 1939. [Edición ilustrada]. Editorial Losada, S.A., Col. Biblioteca Contemporánea, Bs.As., I939; I94I; I943.

La Salamanca. (Misterio Colonial). (Drama en tres actos y en verso). Editorial Losada, S.A., Bs.As., 1943. [Edición ilustrada].

IV. FOLLETOS

Sarmiento evocado ante la juventud universitaria de La Plata. (Bs.As., I9II), 29 págs.

El teatro de Florencio Sánchez. Bs.As., Impr. Albasio y Cía, I9I I. [Conferencia dada en el teatro Odeón de Buenos Aires, 22 págs. Separata de la revista Nosotros, a. IV, t. V, núm. 27, abril de I9II].

La piedra muerta. Martín García, editor, Bs.As., Igr2. [Sobre la Piedra Movediza del Tandil].

La literatura Argentina. [Orígenes, evolución, periodos, influencia, caracteres]. Revista de la Universidad de Buenos Aires, tomo XXI, Bs.As., r913. (Impr. y Casa Editora, Coni). 
Los simbolos universitarios. [Discurso]. La Plata, r9r5.

Historia de la bandera. Bs.As., 1915.

Belgrano: Imprenta y Casa Editora, Coni, Bs.As., r920. [Conf. leída el I8 de junio de 1920 en la celebración del centenario de la muerte del héroe efectuada por la Universidad de Buenos Aires]. 44 pág.

Pellegrini. Imprenta y Casa Editora, Coni, Bs.As., I920. [Conf. leída el 22 de junio de r92I en la inauguración de la Biblioteca Pellegrini, fundada por el Jockey Club]. 32 págs.

Echenique autor de las "Laudationes". Universidad Nacional de Córdoba, Instituto de Estudios Americanistas, número III, Impr. de la Universidad, Córdoba, r938.

Las leyendas de Indias y la novela en la época colonial. Córdoba, 194I. La entrevista de Guayaquil. Imprenta de la Universidad de Buenos Aires, r 947 [separata del tomo VI, $2^{\natural}$ sección, Cap. XI, de la Historia de la Nación Argentina, Bs.As., I947].

V. OTROS TRABAJOS

Bibliografia de Sarmiento. Edición de la Facultad de Ciencias Jurídicas y Sociales de la Universidad de La Plata, Sección de Filosofía y Letras, I9r.

Arcbivo Capitular de Jujuy. [Documentos para las historia argentina], 3 tomos. Bs.As., I9r3-I9I4.

Poesias de Cervantes. (1616-1916). Compiladas y prologadas por Ricardo Rojas. Imprenta Coni, Bs.As., I9r6.

El pensamiento vivo de Sarmiento. Selección y prólogo de Ricardo Rojas. Editorial Losada, S.A., [Col. El pensamiento vivo, Vol. I8], Bs.As., I94I.

FACULTAD DE FILOSOFIA Y LETRAS DE LA UNIVERSIDAD DE BUENOS AIRES. PUBLICACIONES DEL INSTITUTO DE LITERATURA ARGENTINA.

Director: RICARDo RojAS

SECCIÓN DE FOLKLORE

La Música Popular

$I^{2}$ serie. El canto popular

Tomo 1. Ne I. Música precolombiana, con introducción de Ricardo Rojas y consideraciones preliminares por Vicente Forte. 
Tomo II. No I. La música de un códice colonial del siglo XVIl, por Carlos Vega.

$2^{*}$ serie. Ensayos y compilaciones

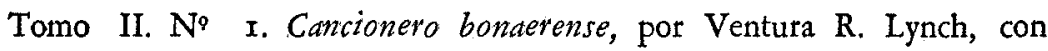
estudio preliminar de Vicente Forte.

$\mathrm{N}^{9}$ 2. Cancionero incaico, por Víctor Guzmán Cáceres, con introducción de Vicente Forte.

Serie especial: T'eorias e Investigationes

La Música Popular Argentina. Canciones y danzas criollas, por Carlos Vega.

Tomo I. Introducción. (En preparación).

Tomo II. Fraseología. Proposición de un nuevo método para la escritura y análisis de las ideas musicales y su aplicación al canto popular, con 717 ejemplos musicales.

\section{Materiales Folklóricos , , , ,}

$3^{3}$ serie. Catálogo de la colección de folklore donada por el Consejo nacional de educación [Completo]

Tomo I. No I. Introducción, por Ricardo Rojas, con un apéndice de Manuel de Ugarriza Aráoz.

$\mathrm{N}$ \% 2. Salta; $\mathrm{N}$ 3. Jujuy

No 4. Tucumán

$\mathrm{N}^{2}$ 5. La Rioja

Tomo II. No I. Santiago del Estero; $\mathrm{N}^{\circ}$ 2. Catamarca

Tomo III. No ${ }^{\circ}$ I. Chaco

$\mathrm{N}^{2} 2$ a 8. Las gobernaciones

Tomo IV. No I. San Juan

$\mathrm{N}$. 2. Mendoza

$\mathrm{N}^{2}$ 3. San Luis

Tomo V. No I. Santa Fe; No 2 y 3. Entre Ríos-Corrientes

Tomo VI. No I. Córdoba

№ 2. Buenos Aires 
Estudio de los Materiales de la Colección de Fol.klore

Tomo I. $N^{\circ}$ I. Romancero, dos tomos, por Ismael Moya, con explicación preliminar de Ricardo Rojas.

No 2. Refranero, por Ismael Moya.

Orígenes del Teatro Nacional

SECCIÓN DE Documentos

$\mathrm{I}^{3}$ serie. Textos dramáticos

Tomo I. Teatro en verso. [Completo].

No r. Una loa colonial en bonor de Carlos III (1761), con noticia de Ricardo Rojas.

No 2. La acción de Maipú. Sainete gauchesco, con noticia de Jorge Max Rohde.

N2 3. La libertad civil. Pieza en un acto (1816), con noticia de Ricardo Rojas.

$\mathrm{N}^{\circ}$ 4. Felipe Segundo, rey de España, tragedia en cinco actos, por el conde Alfieti, traducida por C., en I82o, con noticia de Alfonso Corti.

No 5. Las tres comedias de Da. María Retazos (1821), por el padre Francisco Castañeda, con noticia de Narciso Binayán.

No 6 y 7. Arauco libre. El nuevo Caupolicán, por J. M. Sánchez, con noticias de Dardo Corvalán Mendilaharsu.

No 8. El bijo del Sud. Acto alegórico, anónimo, con noticia de Jorge Max Rohde.

№ 9. Tupac-Amarí (I82I), con noticia de Jorge Max Rohde.

No ro. Rosas y Urquiza en Palermo, por Pedro Echagüe, con noticia de Juan Pablo Echagüe.

No ir. La lealtad más acendrada y Buenos Aires vengadd, por Juan Francisco Martínez, con noticia de Narciso Binayán.

Tomo II. Teatro en verso. [Completo].

No I. Molina, por Manuel Belgrano, con noticia de Ricardo Rojas. 
No 2. El poeta, por José Mármol, con noticia de A. Giménez Pastor.

No 3. El Cruzado, por José Mármol, con noticia de Narciso Binayán.

No 4. Don Tadeo, por Claudio Cuenca, con noticia de Narciso Binayán.

No 5. Muza, por Claudio Cuenca, con noticia de B. Ventura Pessolano.

Tomo III. Teatro en prosa. [Completo].

No I. La batalla de Pasco. Sainete anónimo, con noticia de Jorge Max Rohde.

Ni 2. La revolución de Mayo, por Juan B. Alberdi, con noticia de Arturo Giménez Pastor.

No 3. El Gigante Amapolas, por Juan B. Alberdi, con noticia de Arturo Giménez Pastor.

N2 4. Monteagudo, por Francisco Fernández, con noticia de Narciso Binayán.

No 5. Solané, por Francisco Fernández, noticia de Jorge M. Furt.

No 6. Atar-Gull o una venganza africana, por L. V. Mansilla, con noticia de Carmelo $M$. Bonet.

No 7. El bipócrita político, por P.V.A., con noticia de J.M. Rohde.

No 8. Una víctima de Rosas, por Francisco J. de Acha, con noticia de Narciso Binayán.

Tomo IV. Teatro en verso. [Completo].

No I. El amor de la Estanciera, con noticia de Mariano G. Bosch.

No 2. Las bodas de Cbivico y Pancha. Sainete gauchesco, anónimo, con noticia de Mariano G. Bosch.

No 3. Defensa y triunfo del Tucumán, con noticia de Narciso Binayán.

N 4. Las cuatro épocas, por Bartolomé Mitre, con noticia de B. Ventura Pessolano.

$\mathrm{N}^{2}$ 5. Lucia Miranda, por Miguel Ortega, con noticia de Jorge M. Furt. 
Nó 6. Amor y Virtud, por Pedro Echagüe, con noticia de Margarita Mugnos de Escudero.

Tomo V. Teatro en prosa y verso. [Completo].

No I. La codicia rompe el saco, por José Borrás, con noticia de Narciso Binayán.

No. 2. El sombrero de Don Adolfo, por Casimiro Prieto Valdés, con noticia de Narciso Binayán.

No 3. Don Quijote en Buenos Aires, por Eduardo Sojo, con noticia de María Sara Pinto Alvarez.

No 4. Contra soberbia, bumildad, por Matilde Cuyás, con noticia por C.V.

No 5. Atabualpa, por Nicolás Granada, con noticia de Ismael Moya.

Tomo VI. Teatro en prosa y en verso. [Completo].

N* I. Juan Moreira, de Eduardo Gutiérrez. Primitiva versión teatral de José J. Podestá, con noticia de Carlos Vega.

No 2. Alegria, por Roberto J. Payró, con noticia de J.E.P.

No 3. A través de la vida, por Martín Goycoechea Menéndez, con noticia de C.V.

No 4. La América libre, por Bernabé Demaría, con noticia de Carlos Vega.

Nóticias para la Historia del Teatro Nacional

Tomo I. [En publicación].

No I. Nicolás Granada, por Augusto Raúl Cortázar.

No 2. David Peña, por Aída Cometta Manzoni.

No 3. Iuan Aurelio Casacuberta, por María Antonia Oyuela.

No 4. Abdón Arózteguy, por Dora Corti.

No 5. Justo S. López de Gomara, por A.M. López de Medina.

No 6. Emilio Berisso, por Virginia Etcheto de Badano.

No 7. El soldado fanfarrón, resumen por Celia M. Nieto Arana.

No 8. El triunfo de la naturaleza, resumen por María Josefa Viola. 
$N^{\circ}$ 9. Las esposas vengadas y La Elicene, resúmenes por Celina Sabor de Cortázar.

No ro. Indice Cronológico de datos contenidos en la "Historia del Teatro en Buenos Aires", de Mariano G. Bosch, por Manuel Artacho.

Orígenes de la Novela Argentina

Sección de Documentos

Tomo I. [Completo].

No I. El Matadero, por Esteban Echeverría con noticia de Jorge Max Rohde.

No 2 y 3. El hombre hormiga y El capitán de Patricios, por Juan Maria Gutiérrez, con noticia de Jorge Max Rohde.

No 4. Soledad, por Bartolomé Mitre, noticia de J. Millé Giménez.

No 5. El pozo del Yocci, por Juana Manuela Gorriti, con noticia de Arturo Giménez Pastor.

No 6. El tesoro de los Incas, por Juana Manuela Gorriti, con noticia de José María Monner Sans.

No 7. Esther, por Miguel Cané, con noticia de Ricardo Rojas.

No 8. La familia de Quillango, por José María Cantilo, con noticia de Ricardo Rojas.

No 9. Memorias de un botón de rosa, por $\mathrm{B}$. Mitre, noticia de N. Binayán.

No Io. La familia de Sconner, por Miguel Cané, con noticia de Narciso Binayán.

$\mathrm{N}^{2}$ II. Tobias o la cárcel a la vela, por Juan Bautista, Alberdi, con noticia de Ricardo Rojas.

No 12. La Rinconada, por Pedro Echagüe, con noticia de Juan Pablo Echagüe.

Tomo II. [En publicación].

No 1. El hogar en la pampa, por Santiago Estrada, con noticia de Narciso Binayán. 
Tomo II. [Completo].

\section{CRítícA}

№ I. Un dramaturgo olvidado, don Francisco Fernández y sus "Obras dramáticas", por Ricardo Rojas.

No 2. El "Filippo" de Alfieri en Buenos Aires, por Alfonso Corti.

No 3. Angel de Estrada, por Jorge Max Rohde.

No 4. Sarmiento critico teatral, por Juan Pablo Echagüe.

$N^{\circ}$ 5. Elogio de Joaquín V. González, por Ricardo Rojas.

No 6. Epistolario de Sarmiento, por Augusto Belín Sarmiento.

N' 7. El teatro de Ernesto Herrera, por Carmelo M. Bonet.

No 8. Belisario J. Montero, por Jorge Max Rohde.

No 9. Florencio Sánchez, por Dora Corti.

No ro. Otros versos de Martín Fierro, por Ricardo Rojas.

$\mathrm{N}^{\circ}$ II. Himnos quicbuas, por Ricardo Rojas.

N' 12. El costumbrismo en el teatro de Julio Sánchez Gardel, por Ismael Moya.

$\mathrm{N}^{\circ}$ 13. Ezequiel Soria, zarzuelista criollo, por Ismael Moya.

Tamo II. [En publicación].

No r. Gente de novela, por Carmelo M. Bonet.

No 2. El americanismo en el seatro y la prédica de Sarmiento, por Ismael Moya.

No 3. Martiniano Leguizamón y su égloga "Calandria", por Julia Grifone.

No 4. Alfonsina Stomi, por María Teresa Orosco.

Otras Publicaciones

Poesias, por Antonino Lamberti, con prólogos de Mariano de Vedia y Martiniano Leguizamón.

Diálogo de las sombras $y$ otras páginas de Emilio Becher, con prólogo de Ricardo Rojas.

\section{ESTUDIOS PRELIMINARES Y PROLOGOS}

Biblioteca Argentina, publicada bajo la dirección de Ricardo Rojas, por Juan Roldán y Cía., en Buenos Aires, entre los años r915 y 1928. 
[Cada volumen contiene un prólogo del director, una somera noticia biobibliográfica sobre el autor y el libro, con indicación de las fuentes utilizadas y notas críticas sobre el mismo].

I. Doctrina Democrática, de Mariano Moreno.

2. Dogma Socialista, de Esteban Echeverría.

3. Bases, de Juan B. Alberdi.

4. Educación popular, de Domingo F. Sarmiento.

5. Tierras públicas, de Nicolás Avellaneda.

6. Tragedias, de Juan Cruz Varela.

7. Obras politicas, de Bernardo Monteagudo.

8. Comprobaciones bistóricas (primera parte), de Bartolomé Mitre.

9. Luz del dia en América, de Juan B. Alberdi.

ro. Peregrino en Babilonia, de Luis de Tejeda.

Ix. Reflexiones, de J.I. de Gorriti.

12. Facundo, de Domingo F. Sarmiento.

13. Descripción colonial (libro I), de fray Reginaldo de Lizárraga.

14. Descripción colonial (libro II), de fray Reginaldo de Lizárraga.

15. Comprobaciones históricas (segunda parte), de Bartolomé Mitre.

16. (al i8) Debate histórico (en III tomos), de Vicente F. López.

19. Martin Fierro, de José Hernández.

20. Relaciones del Estado con la Iglesia, de Dalmacio Vélez Sársfield.

21. Recuerdos de Provincia, de Domingo F. Sarmiento.

22. La politica liberal bajo la tirania de Rosas, de J.M. Estrada.

23. (al 26) Historia de Belgrano $y$ de la independencia argentina (en IV tomos), de Bartolomé Mitre.

27. Discursos (Oraciones cívicas), de Nicolás Avellaneda.

28. Condición del extranjero en América, de Domingo F. Sarmiento.

29. Diez ensayos, de Nicolás Avellaneda.

La lira argentina. [Colección de piezas poéticas dadas a luz en Buenos Aires durante la guerra de su Independencia]. Noticia de Ricardo Rojas. Librería "La Facultad", Juan Roldán y Cía., Bs.As., I924. Joaquin V. González, por Ricardo Rojas, en J.V.González, Obras Completas, Bs. As., 1937, volumen XXV (págs. 253-273).

Memorias de un hombre de teatro, por Enrique García Velloso. Prólogo de Ricardo Rojas, Bs.As., Editorial Guillermo Kraft, I94I.

Comentarios reales de los incas, de Garcilaso de la Vega (El Inca). Prólogo de Ricardo Rojas. [Texto completo, sobre la edición principe 
(Lisboa, I609) de Ángel Rosenblat], 2 tomos. Emecé Editores, S.A., Bs.As., 1943 .

Historia de la Nación Argentina, Edición de la Academia Nacional de la Historia. Tomo VI, La entrevista de Guayaquil, Bs.As., I947. [Ver: Folletos]; y Génesis de la literatura argentina (1537-1862), en Tomo VIII, Bs. As., r945; [hay $2^{\mathrm{a}}$ edición, Librería "El Ateneo", T. VI en 1948 y T. VIII, en 1947 ].

La campaña del Ejército Grande, por Domingo Faustino Sarmiento. Prólogo de Ricardo Rojas. Con ilustraciones de W. Melgarejo Muñoz. Edición de Amigos del Libro, Buenos Aires, 1956.

La aurora en Copacabana, de Calderón de la Barca. Estudio preliminar de Ricardo Rojas. Edición anotada por Antonio Pagés Larraya. Librería Hachette, S. A., Col. "El pasado argentino", Bs. As., 1956.

\section{DISCOGRAFIA}

El pais de la selva. Colección El Libro Sonoro. [Discos Inter-Bas], Editorial Guillermo Kraft Ltda., Bs. As., I946. Prólogo grabado por Ricardo Rojas. (Disco LS III); Relator Buenaventura Luna y su conjunto folklórico (Disco LS $\times 12$ );

El nina-quiru (Disco LS II3); y La Telesita (Disco LS I I4). La edición contiene un ejemplar del citado libro, ilustrado por Alfredo Gramajo Gutiérrez (con dos discos adicionales).

\section{TRADUCCIONES}

\section{A). LIBROS}

El Cristo Invisible: 'The Invisible Christ'. Traducción al inglés de W. E. Browning, Cincinnati, I93I.

El Santo de la Espada: O Santo Da Espada (San Martín). Traducción al portugués de Lauro Escorel. Prefacio de Augusto Frederico Schmidt. Edición del Ministerio de Relaciones Exteriores, Servicio de Publicaciones, Col. Brasileira de Autores Argentinos, vol. núm. 7 (Imprenta Nacional), Río de Janeiro, Brasil, I948.

B). Fragmentos

La canzone dell'assenza; Orazione; Epistola a Emilio Becber. En Antologia della Poesia Argentina Moderna, traducción y notas de Folco Tes- 
tena, Ediciones "Alpes", Milano, I927; reeditado con el título Poeti Argentini, Libreria Editrice Attilio Moro, Bs. As., I948.

Trozos de prosa y verso. Traducción al italiano por $\mathrm{G}$. Marone, en $l l$ libro della Pampa, vol. I (Antologia di scrittori Argentini, Gino Carabba, editore, Lanciano, 1937).

Le "Kakuy": En Le payasage et l'âme argentins, trad. de Arturo Orzábal Quintana. Comisión de Cooperación Intelectual, Bs. Aires., I938.

La sangre del sol: An die Sonne, traducción al alemán por Robert Lehman-Nietzsche, en Aus der Pampa, Verlag Von Felix Meiner, Leipzig, I940.

El incubo: The Incubus, traducido al inglés por Harriet de Onís, en The Golden Land, An Antbology of Latin American Folklore in Literature, Alfred A. Knopf, New York, 1948.

Our Native Land: En Argentine Anthology, compiled by S. W. de Ferdkin, Oxford University Press, London, 1948.

Nota final

Detallamos a continuación el plan de Obras Completas de Ricardo Rojas, que ha iniciado la Editorial Losada, S. A., y los títulos orgánicos de la misma.

Primera Serie: Historia de la literatura argentina (8 volúmenes).

Segunda Serie: Poemas de un Mundo Nuevo (Io volúmenes): 9, Poesías, desde La Victoria del Hombre hasta El Albatros; Io, El País de la Selva; Ir, Ollantay. Un Titan de los Andes; I2, Elelin. La Casa Colonial. La Salamanca; 13, El Cristo Invisible; 14 , Los mitos bistóricos; 15, El Ucumar y otros cuentos; I6, Archipiélago; I7, El Santo de la Espada; 18, El profeta de la Pampa.

Tercera Serie: Filosofia de la argentinidad (6 volúmenes): 19, La restauración nacionalista; 20, Blasón de Plata. Definición de nuestro nacionalismo; 21, La argentinidad; 22, Las provincias; 23, El radicalismo de mañana; 24, Eurindia.

Cuarta Serie: Entre España y América (6 volúmenes): 25, Retablo Español; 26, Cervantes; 27, Estudios bispánicos; 28, Silabario de la decoración americana; 29. Himnos quichuas y otros ensayos; 30, La entrevista de Guayaquil y otras investigaciones.

Quinta serie: Memorias (ro volúmenes): 31, Vida de mi padre; 32, El Mataquito; 33, Entre bobemios y doctores; 34, Viajes; 35, Universidad; 36 , Política; 37, Jornadas; 38, 39 y 40, Discursos. 
La vida y la obra de Ricardo Rojas ha merecido títulos honoríficos de varias universidades americanas y figura como miembro de numerosas academias e instituciones culturales. En su obra recordamos el Premio Nacional (I92r), otorgado a la primera edición de Historia de la literatura argentina; el Primer Premio de Teatro, dado por la Comisión Nacional de Cultura a sus piezas, Ollantay (1939) y La Salamanca (1943); y el Gran Premio de Honor, que la Sociedad Argentina de Escritores confirió a su vida de Sarmiento, El profeta de la Pampa (I946). A este respecto es de gran utilidad el folleto titulado, El Centro de Derecho y Ciencias Sociales solicita el Premio Nóbel de Letras para la obra de Ricardo Rojas al cumplirse el cincuentenario de su primer libro: La Victoria del Hombre, [s. p. e., I6 pág.; 1953; hay edición en francés], con una bibliografía por orden cronológico y algunos detalles críticos o biográficos).

Horacio Jorge Becco, Buenos Aires, Argentina. 